\title{
SWOFT Analysis of B2C Garment Marketing in China
}

\author{
Weichun Li \\ Jiangxi Institute of Fashion Technology \\ Nanchang, China 330201
}

\begin{abstract}
With the rising and development of online shopping, the B2C market size is expanding unceasingly across China, especially in the garment field, the B2C garment business has become a mature category on the online trading platforms and been popular in more and more consumers. However, there are still lots of problems existing in the B2C garment business such as product quality, service, technique and safety. Based on the SWOT method, this article analyzes the strengths weaknesses, opportunities and threats existing in the $\mathrm{B2C}$ garment marketing in the country and provides suggestions for the development of B2C garment marketing as references.
\end{abstract}

Keywords—B2C; garment market; SWOT

\section{INTRODUCTION}

In recent years, with the continuous development and popularization of Internet, the number of Internet users has been increasing in China, and the proportion of online shopping increases in a large scale. In 2015, the online shopping amount reached 3.8 trillion yuan in China, and the online shopping is entering an Internet time developing at a high speed. And the $\mathrm{B} 2 \mathrm{C}$ mode provides consumers with a new shopping environment-online stores where consumers may purchase and pay online, saving a lot of time. In the future, the $\mathrm{B} 2 \mathrm{C}$ model will continue to expand the business size, especially in the B2C garment field, the garment business development has been relatively mature at home, and the garment sales online has formed a flourishing market situation.

\section{STRENGTHS}

Costs reduced effectively: Compared to physical stores, the garment products online have lower prices, and high value products can be purchased with lower prices, which save money. Besides, it's unnecessary for consumers to spend more time selecting in physical stores, mobile phones and computers can be used for online purchase anytime and anywhere, it is out of the control of time or place so as to reduce the purchase time, energy and physical strength of consumers. Seen from the garment enterprises, the online sales channels may reduce costs in transport, distribution, advertisement and management arising in the intermediate stages. The lower costs make it better to well run the enterprises, and the increased profits make it possible for more investment to new product development and market expansion.
Purchase efficiency improved: compared to retails in traditional stores, the $\mathrm{B} 2 \mathrm{C}$ garment marketing focuses on individuation so as to increase the purchase efficiency and achieve the marketing interaction. On the one hand, consumers may know the marketing information posted by garment enterprises anytime and anywhere and select diverse products according to demands of their own, meanwhile, suggestions or comments about products can be directly submitted to the dealers online. On the other hand, enterprises may collect data of consumers and provide individualized products and service, besides, the timely responses to consumers' suggestions or comments may win favorable expression and trust of consumers to further intensify the consumers' loyalty to the products concerned.

Enterprise management mode much systematized: the B2C garment marketing relies on the database systems of merchants, which are in a low cost, high volume, timely update and easy to manage. According to the data and consumption records of consumers, merchants may fully understand the demands of different consumers, which makes it easy for enterprises to carry out customized marketing to consumers, intensify enterprises' responses to market and increase the enterprises' market competitiveness. On the other hand, meeting the needs of consumers may improve the satisfaction and loyalty of consumers and achieve the incremental purchase and cross purchase of garment products.

Marketing effect much measured: the B2C garment marketing has timely and accurate statistical mechanism, merchants may obtain consumers' data and master consumers' number and quality through channels as survey, form, registration, purchase and so on. In addition, merchants may conduct online monitoring on the advertisement effect through consumers' behaviors recorded via advertisements and websites and measure the advertisement effect. From which, merchants will find the ways that consumers use to browse websites of the enterprises, and the consumers' preferences to different garment products can be measured via click rate, page views and purchase rate.

\section{WEAKNESS}

Garment products distorted: for the online purchase is virtual, and the pictures that most enterprises use for product description are copied, and the literal statements often boast the quality, color and thickness, inducing consumers for purchase. Meanwhile, most consumers select products as per 
the pictures and statements shown by merchants, as a result, after receiving the garment products, the demonstration and try-on are out of expectation, which cause complaints and lowered dissatisfaction of consumers, and the distrust of consumers to online product purchase has influenced the B2C garment market development.

Try-on of garment products: During the operation of traditional physical stores, generally consumers will try on before purchase through direct contact with the garment products to touch the product quality, color, style, fabric and so on, and then decide to buy or not according to the product satisfaction. However, as for the product online, consumers can only image indirectly the products through pictures where models try them on, as a result, after receiving the garment products, they are not satisfactory, and the consumers even return the products. The try-on problem is an important factor to limit the $\mathrm{B} 2 \mathrm{C}$ garment market development, which has a direct impact on consumers' desires to buy, so it is a major bottleneck for consumers to purchase garment products online

After-sale service: Physical garment stores have a lower probability for product returns, because consumers will generally try them on before purchase, even if the product has to be returned, as long as the product is not used, it can be returned for renewal at merchants concerned. Yet, in the B2C garment market, due to the product distortion and failure in try-on, it has a higher probability for product returns or renewal, and the product size, color and quality deviation all will affect the mentality and behavior of consumers for product returns or renewal. However, in the $\mathrm{B} 2 \mathrm{C}$ market, the procedures for product returns or renewal are complex, and the customers have to communicate with merchants and apply for the product returns or renewal, and then the products will be delivered by couriers to the merchants, if the product is in a good quality, the consumer concerned has to bear relevant freight. The after-sale service of the B2C garment market is a significant factor to affect consumers' purchase.

Logistics and distribution: the $\mathrm{B} 2 \mathrm{C}$ garment business needs to cooperate with a third logistics agent, yet the logistics development is far behind the pace of E-commerce in China, in 2015, the logistics and distribution for "Nov 11" fully exposed the problems existing in logistics such as time delay for delivery, inaccurate places for delivery, product damages and so on. In particular, after the promotion activities in holidays by merchants, phenomena as fully filled logistics warehouses were reported frequently. In order to improve the delivery efficiency, some logistics agents signed for product reception without permission of consumers, which caused conflicts between consumers and couriers. The problems related to logistics and distribution have triggered consumers' dissatisfaction with merchants, the complaints and reduced desires to purchase have directly blocked the B2C garment market development.

\section{OPPORTUNITIES}

E-commerce development supported by governments: The E-commerce has made a rapid progress in China, which has become a new driving force for the economic development. A series of E-commerce related policies have been published to foster the development of e-commerce. In 2015, the Opinions of the State Council of the People's Republic of China on Intensively Developing the E-commerce and Accelerating the Cultivation of New Economic Power proposed an easy environment for the development of e-commerce; the Guiding Opinions of the General Office of the State Council of the People's Republic of China on Accelerating the Development of Electronic Commerce in Rural Areas opened up the rural market for E-commerce development. In addition, the state has also promulgated relevant laws and regulations to regulate online shopping information management, trading behavior, logistics and distribution, and constantly promote the legalization and standardized development of e-commerce operation.

B2C market size expanding unceasingly: during 2010-2011, the independent B2C market broke out, traditional enterprises began to access to Internet in this stage. During 2012-2014, the proportion of e-commerce increased gradually in the overall business, of which, the B2C market achieved a business amount of 1.26 trillion yuan in 2014. In 2015, the online shopping market size reached 3.8 trillion yuan, increased by $37.20 \%$, still at a high level of growth. In coming years, with the market standardized increasingly, the B2C will further expand the market share, occupying a current market share of about $50 \%$, it will increase at an average growth rate of about $30 \%$ annually and it is expected to reach $70 \%$ of online business in 2020 ,

Development of mobile e-commerce: Mobile e-commerce is a $\mathrm{B} 2 \mathrm{~B}$ or $\mathrm{B} 2 \mathrm{C}$ business achieved through mobile terminals such as mobile phones, PDAs, pocket PC and so on. Nowadays, consumers are also aware of the convenience of mobile shopping, with the mobile online shopping open, consumers may purchase garment products anytime and anywhere and enjoy the convenience and freedom of online shopping. At present, the Internet mobile phone users have exceeded 900 million in China, which has a broader market prospect. With diverse software used for shopping online and the opening and popularization of mobile online malls, the sales of B2C garment will increase greatly.

\section{THREATS}

Network safety threats: Due to the opening of B2C garment market, consumers' personal data are often disclosed because of network defects, besides, the direct online transactions need payment platforms with bank cards bound for operation, which cause doubts to safety of online shopping. Besides, most have poor awareness of the safety, which greatly reduces consumers' confidence in the online shopping and hinders the development of B2C garment market.

Hot competition in garment market: the competition in garment industry becomes hot increasingly, new brands and styles appear one after another, how to occupy market shares in the hot market competition and better satisfy consumers than opponents while meeting the changing demands of consumers have been a difficult problem in marketing for garment enterprises. More and more industrial brands depend on continuous transformation and upgrade to meet diversified 
demands of consumers in order to win more opportunities for medium and small-sized enterprises in market.

Ill-formed online market orders: In recent years, the B2C garment market has been rising in a raid speed and maintained a trend of sustainable growth. However, during the rapid development, the problems of ill-formed market orders have gradually appeared. Seen from the garment enterprises, there are many ill-formed behaviors, as fake garment products, lowquality garment products, void promises for after sales service, etc. which bring doubts of consumers to the online garment products, instead, they prefer to traditional physical stores, thus, it is a huge loss of customers for the B2C garment market, doing bad to the development of B2C garment market.

\section{CONCLUSION}

The SWOT analysis of the B2C garment marketing in China shows that the $\mathrm{B} 2 \mathrm{C}$ garment market has many strengths: lower costs, higher efficiency, systematic enterprise management and measurable marketing effect, all of which have placed a solid foundation for the B2C garment market development in the country. Meanwhile, there are more opportunities for the development of the B2C garment market: Governmental support to E-commerce provides drives for the steady development of the B2C garment market, the development of mobile E-commerce expands customer groups for the $\mathrm{B} 2 \mathrm{C}$ garment market, and the increased market size of B2C garment market brings a bright future for the B2C garment market. Based on the opportunities and advantages in development, the garment enterprises should catch them for network marketing and make use of low costs and high efficiency to provide consumers with more valuable garment products and after-sale service.

After all there are still many weaknesses in the B2C garment market in the country such as product description distortion, problems of product try-on, after-sale service and logistics and distribution, all of which have restricted the development of the B2C garment market to some degree. In addition, the $\mathrm{B} 2 \mathrm{C}$ garment market also faces a huge threat from external environment: fierce competition in the garment market, ill-formed online market orders, network safety and the like, all greatly reduce consumers' confidence in the online shopping, hindering the $\mathrm{B} 2 \mathrm{C}$ garment market development. Accordingly the garment enterprises should improve the product quality, set corporate brands and improve after-sale service while providing quality products and services, intensify the competitiveness of enterprises, conduct internal adjustments to adapt to external threats so as to promote the development of the B2C garment market in the country.

\section{REFERENCES}

[1] Dong Yan, Study on Marketing Strategies of B2C-based Garment Market in China [D]. Tianjin University, 2012

[2] Xu Ying, Empirical Study on Customer Experiencing Factors for B2C Garment Market [D]. Qingdao University, 2012.

[3] Yang Jiao, Study on Marketing Strategies of B2C-Based Online Women's Dress Brands [D]. Wuhan Textile University, 2012.
[4] Wang Ruiqing, Study on B2C-based Online Marketing of Garment Enterprises in China, Suggestions on the Basis of $4 \mathrm{Cs}[\mathrm{J}]$. Shandong Textile Economy, 2015, 07:8-11.

[5] Zhao Xin, Fu Shishen, Study on E-Commerce of Textile Garment and Online Marketing in China [J]. Progress in Textile Science \& Technology, 2013, 04: 84-86+96.

[6] Tang Ling, The B2C Marketing Transaction Reaching 91.62 billion yuan in the 3rd Quarter, China, China Textile News, 2014-11-13001.

[7] Study Report of Software E-commerce in China, 2015-IResearchWtoutiao.

[8] (http://mp.weixin.qq.com/s?_biz=MjM5NDA1ODk2MA==\&mid=405 $120057 \& \mathrm{idx}=4 \& \mathrm{sn}=8 \mathrm{f} 6 \mathrm{e} 262867 \mathrm{c} 69 \mathrm{dbde} 8800 \mathrm{~d} 286 \mathrm{a} 4 \mathrm{f} 9 \mathrm{~d} 03 \&$ scene $=0 \# \mathrm{r}$ d). 